Boise State University

ScholarWorks

Community and Environmental Health Faculty

Department of Community and Environmental

Publications and Presentations

Health

$1-1-2006$

\title{
The Psychological Effects of Exposure to Wartime Trauma in Bosnian Residents and Refugees: Implications for Treatment and Service Provision
}

Sandina Begic

Clark University

Theodore McDonald

Boise State University 


\title{
The Psychological Effects of Exposure to Wartime Trauma in Bosnian ${ }^{1}$ Residents and Refugees: Implications for Treatment and Service Provision
}

\author{
Sandina Begic \\ Department of Psychology \\ Clark University
}

\author{
Theodore W. McDonald ${ }^{2}$ \\ Department of Community \\ and Environmental Health \\ Boise State University
}

\begin{abstract}
It has been widely reported that exposure to war-related trauma leads to psychological distress in human beings, and it has been hypothesized that this psychological distress may be compounded when people leave their war-torn countries and begin their lives as refugees in a new country. In this study, we explored whether a systematic relationship existed between the level of traumatic wartime events experienced by Bosnian residents and refugees living in the western United States and their levels of post-traumatic stress disorder (PTSD), anxiety, and depression. We also explored whether differences in levels of these mental health problems existed between Bosnian residents and refugees. The results indicated that level of exposure to wartime trauma was significantly correlated to mental health problems on all three dimensions. Bosnian refugees reported significantly greater levels of PTSD than members of their Bosnian resident cohort, but not greater levels of anxiety or depression.
\end{abstract}

During the past several decades, an increasing number of researchers have shown an interest in studying issues related to refugees. This is likely the case, at least in part, because the wars of the twentieth century are considered by many to have been increasingly destructive. Record numbers of refugees have been displaced by a number of these wars. For example, whereas in 1970 there were an estimated 2.5 million refugees scattered around the world, by 2000 , this number was estimated to be 40 million or even more (Colic-Peisker \& Walker, 2003; Pumariega, Rothe, \& Pumariega, 2005). Numerous researchers have studied members of several major populations affected by exposure to war trauma and forced migration. These populations include people from Southeast Asia (particularly Cambodians, Hmong, Laotians, and Vietnamese; e.g., Beiser \& Fleming, 1986; Beiser \& Hou, 1986; Chung \& Singer, 1995; Clarke, Sack, \& Goff, 1993; Flaskerud \& Anh, 1988) and South and Central America (e.g., Espino, 1991; Gafner \& Benson, 2001; Thompson \& McGorry, 1995). More recently, many researchers (e.g., Carballo et al., 2004; Geltman, Augustyn, Barnett, Klass, \& Groves, 2000; Kocijan-Hercigonia, Rijavec, Marusic, \& Hercigonja, 1998; Miller et al., 2002a; Miller et al., 2002b; Mooren \& Kleber, 2001; Powell et al., 2003; Thulesius \& Hakansson, 1999; Weine et al., 1995; Weine et al., 1998) have focused on refugees from the short (1992-1995) but brutal war in Bosnia, which reportedly displaced some two million persons, resulted in tens of thousands killed, and featured the worst examples of genocide (more commonly referred in the Bosnian context as "ethnic cleansing") in Europe since the Second World War (Sudetic, 1998).

The elements of the refugee experience most focused upon by psychologists and other mental health professionals have been the psychological effects of exposure to war trauma and forced relocation. Numerous researchers have reported, when studying either Bosnian refugees or refugees from other countries, that exposure to war trauma can have a profound impact on the mental health of survivors. Many of these researchers have reported post-traumatic stress disorder (PTSD) to be prevalent among refugees (Ajdukovic, 1998; Clarke et al., 1993; Miller et al., 2002a; Thompson \& McGorry, 1995; Thulesius \& Hakansson, 1999; Weine et al., 1995; Weine et al., 1998; Witmer \& Culver, 2001). For example, in a longitudinal assessment of PTSD in Bosnian refugees in the Chicago area, Weine 
and his colleagues (1998) found that nearly $75 \%$ of their sample suffered diagnosable levels of PTSD at an initial assessment, and that PTSD was particularly prominent and severe in older refugees. Thulesius and Hakansson (1999), in a study of Bosnian refugees in Sweden, estimated that the prevalence of PTSD among these refugees was between $18 \%-33 \%$, compared to a prevalence rate of between $.3 \%$ and $1 \%$ in a non-refugee comparison group. Although some researchers (e.g., Silove, 1999) have questioned whether PTSD rates are indeed this high among refugees, the vast majority of the studies in this area suggest that post-traumatic stress is a common consequence of exposure to wartime trauma. According to Herman (1992), the complexity and severity of the PTSD depends largely on the length and magnitude of the trauma, with persons exposed to prolonged, repeated, and particularly violent trauma developing more severe PTSD.

Although it seems to be reported on most frequently, PTSD is not the only mental health consequence stemming from exposure to wartime experiences. Various other types of war-induced psychological difficulties have been reported throughout the mental health literature, including anxiety, depression, and somatic distress (Beiser \& Fleming, 1986; Chung \& Singer, 1995; Clarke et al., 1993). Depression seems a common consequence of wartime trauma, and it appears to be particularly prevalent in refugees (e.g., Mghir, Freed, Baskin, \& Katon, 1995). Perhaps not surprisingly, depression has been reported to exist with PTSD among many refugees (Smith, Perrin, Yule, \& Rabe-Hesketh, 2001; Thabet, Abed, \& Vostanis, 2004; Weine et al., 1995). Thabet and his colleagues (2004), as well as others (e.g., Mollica, McInnes, Poole, \& Tor, 1998; Sack, Clarke, \& Seeley, 1996) have argued that it is extremely difficult to determine whether depression and PTSD develop independently, or whether the experience of PTSD, coupled with grieving over war-related losses and the experience of relocation, leads to the development of depression. However, it remains clear that many refugees who have survived war do often experience pathological levels of depression and other mental health problems, and that these problems may perseverate long after exposure to the trauma (Mollica, 2001).

The issue of whether mental health problems such as PTSD and depression, if originally caused by exposure to wartime trauma, are exacerbated by the experience of being a refugee is an important one. An implicit assumption in refugee resettlement seems to be that refugees, once removed from the setting in which they were victimized or persecuted, should show rapid improvements in mental health and general well being. However, research suggests this may not be the case. For example, Miller and his colleagues (2002a), in a review of existing literature on refugees, reported that experiencing exile may considerably contribute to psychological distress among refugees. Other researchers (e.g., Hunt \& Gakenyi, 2005; Keyes, 2000; Spasojevic et al., 2000) agree, maintaining that the experience of being a refugee in a new country may compound, rather than reduce, mental health difficulties caused by exposure to wartime trauma, as refugees often struggle with personal and group identity issues, transition from being known and respected members of one community to anonymous and functionally illiterate residents of another, endure lack of social support, and are often unemployed or underemployed due to their inability to speak the language of the host country or the non-equivalency of their professional training. If it is true that the experience of being a refugee may exacerbate psychological distress incurred by exposure to wartime trauma, this information has real and important implications for mental health outreach and provision, particularly in nations such as Canada, Germany, Sweden, the United Kingdom, and the United States, all of which have traditionally accepted large numbers of refugees from war-torn countries.

The purpose of the present study was to explore several important questions related to mental health status in war survivors. First, we explored whether a systematic relationship existed between the level of exposure to wartime trauma and psychological distress (i.e., anxiety, depression, and PTSD) in Bosnian war survivors (both Bosnian residents and refugees living in the western United States). We anticipated that, consistent with the results reported by past researchers (e.g., Ajdukovic, 1998; Herman, 1992), greater exposure to wartime trauma would be associated with greater levels of anxiety, depression, and PTSD. Second, we explored whether systematic differences in psychological distress existed between Bosnian residents and refugees. We anticipated that, consistent with the results of several researchers (e.g., Miller et al., 2002a; Miller et al., 2002b; Hunt \& Gakenyi, 2005), Bosnian refugees, perhaps due to the difficulties associated with beginning a new life in a foreign country, would report greater levels of anxiety, depression, and PTSD than Bosnian residents. 


\section{Method}

Participants

The participants in this study were 128 adults who had lived in Bosnia for at least a portion of the 1992-1995 war. Sixty-five of the participants (or 50.8\% of the total sample) were current residents of Bosnia, with the largest numbers currently residing in the Bosnian capital of Sarajevo (38 persons, or 58.5\% of the Bosnian resident sample, resided in Sarajevo), and the central Bosnian cities of Zenica $(11 ; 16.9 \%)$ and Ilijas $(7 ; 10.8 \%$; nine other participants resided in six other cities or towns). Sixty-three participants (49.2\% of the total sample) were currently living in the western United States, with all 63 reporting their current residence to be Boise, Idaho.

The participants were nearly equally represented in terms of gender, with $65(50.8 \%)$ reporting themselves to be women and $63(49.2 \%)$ reporting themselves to be men (there was no systematic difference in gender distribution between participants living in Bosnia or in the United States). The mean age of the participants was 39.13 years ( $s d$ $=13.37)$, with the refugees in the United States $(M=41.89, s d=11.67)$ being significantly older than the Bosnian residents $(M=36.45, s d=14.42), t(126)=-2.34, p<.05$. The majority of the participants reported themselves to be either married (72 participants, or $56.2 \%$ of the sample) or single $(38 ; 29.7 \%)$, with smaller numbers reporting themselves to be widowed $(26 ; 12.5 \%)$ or divorced $(2 ; 1.6 \%)$. A significant difference was found between the two groups with respect to marital status, with the largest group of Bosnian residents reporting being single (47.7\%) and the largest group of refugees in the United States reporting themselves to be married $(76.2 \%), \chi^{2}(\mathrm{df}=3)=25.13, p$ $<.001$. No differences in religious affiliation were found between the two groups, with over $80 \%$ of the participants in both groups reporting themselves to be Muslim. Over $85 \%$ of the participants reported having at least completed high school, and no educational differences were found between the Bosnian residents and refugees.

\section{Materials}

Two assessment measures were used in this study. The first measure was the Harvard Trauma Questionnaire (HTQ; Allden et al., 1998a). The HTQ was developed by researchers at the Harvard Program in Refugee Trauma over a decade ago, and has been used with members of various populations that have been affected by war-related trauma (Allden et al., 1998c; Mollica, Caspi-Yavin, Bollini, Truong, Tor, \& Lavelle, 1992). The HTQ consists of four parts. Part I consists of 46 trauma-related events, and a dichotomous "Yes" or "No" response format is used to indicate whether or not the respondents experienced the relevant type of trauma addressed by each item. The trauma events include: 1) material deprivation (e.g., lack of food or water); 2) war-like conditions (e.g., exposure to sniper fire); 3) bodily injury (e.g., being beaten or raped); 4) forced confinement and coercion (e.g., being kidnapped or imprisoned); 5) being forced to harm others (e.g., being forced to damage another person's property); 6) disappearance, death, or injury of loved ones (e.g., disappearance or kidnapping of spouse); and 7) witnessing violence to others (e.g., witnessing rape or sexual abuse). Part II includes two open-ended questions asking respondents to report the most traumatic events they have experienced. Part III includes six questions asking about whether or not respondents experienced brain injury or unconsciousness from such acts as beatings, suffocation, or starvation. Part IV includes 40 items; the first 16 items ask questions created to assess PTSD symptoms, and the remaining 24 items ask questions related to the respondents' perceptions of their ability to function in day-to-day life (Allden et al., 1998c). The Bosnia-Herzegovina version of the HTQ was deliberately modified from previously used versions of the HTQ to be culturally appropriate for survivors of the war in Bosnia. It was carefully translated into common Bosnian vernacular so that it could be easily understood by all adult respondents, and was tested and validated over a period of two years (Allden et al., 1998c).

The second assessment measure was the Hopkins Symptom Checklist-25 (HSCL-25), developed from the longer and more commonly used Symptom Checklist-90 (Allden et al., 1998b; Allden et al., 1998c; Derogatis, Lipman, \& Covi, 1973; Parloff, Kelman, \& Frank, 1954). The HSCL-25 contains two parts. Part I consists of 10 items related to anxiety symptoms (e.g., heart pounding or racing, spells of terror or panic), and Part II consists of 15 items related to symptoms of depression (e.g., feeling hopeless about the future, feelings of worthlessness). Each of the 25 items on the HSCL-25 features a four-point response scale, with values ranging from "not at all" to "extremely." The HSCL25 has been validated and used successfully with other refugee populations (Allden et al., 1998c; Mollica, Wyshak, de Marneffe, Khuon, \& Lavelle, 1987), and the current version was translated with care into common Bosnian vernacular by researchers at the Harvard Program in Refugee Trauma. 


\section{Procedure}

The first author and several native Bosnian assistants distributed copies of the HTQ and HSCL-25 during two phases. During the summer of 2004, they delivered copies of the instruments to residents in Bosnia. Copies of the surveys were handed to a convenience sample of persons found in a variety of locations, including public areas (e.g., cafes and parks) and private homes. Those people who agreed to complete the survey materials were afforded the opportunity to individually complete them immediately and return them by hand, or to complete the surveys at a time of their choice and to mail the completed surveys to the first author at a later date. ${ }^{3}$ During the fall of 2004 , the first author and her assistants distributed copies of the two instruments to a convenience sample of Bosnian refugees in Boise, Idaho, which is home to approximately 3,000 Bosnian refugees. Again, those people who agreed to complete the survey were allowed to complete them immediately and return them by hand or to complete them at a later time and mail them to the first author.

\section{Results}

Prior to conducting our initial analysis of the relationship between summed trauma experiences and levels of PTSD, anxiety, and depression, we conducted several analyses to determine whether summed trauma experiences were also related to the demographic variables country of residence, age, marital status, and gender. These analyses revealed that the refugees in the United States reported having been exposed to significantly more traumatic experiences $(M=$ 91.92, $S D=24.18)$ than their counterparts living in Bosnia $(M=81.19, S D=27.51), t(126)=-2.34, p<.05$, and it was also found that age was positively and significantly correlated with traumatic experiences, such that older respondents reported having been exposed to greater trauma than younger respondents, $r(124)=.48, p<.001$. A statistically significant effect was also found with respect to marital status, $F(3,124)=13.00, p<.001$. As seen in Table 1, post-hoc Tukey tests revealed that this effect was accounted for by single respondents reporting having had significantly less exposure to traumatic experiences than married respondents and widowed respondents, and by married respondents also reporting significantly less exposure to traumatic experiences than widowed respondents. No statistically significant difference in reported trauma exposure was found between men and women. However, a non-significant trend $(p<.10)$ suggested that women $(M=90.35, S D=27.36)$ were exposed to somewhat more trauma experiences than men $(M=82.46, S D=24.92)$. In light of these findings, we concluded that it would be appropriate to assess the relationship between summed trauma scores and levels of PTSD, anxiety, and depression while controlling for the variance accounted for by country of residence, age, marital status, and gender. As seen in Table 2, when we did so, we found that summed trauma experiences were strongly and positively correlated with levels of PTSD, anxiety, and depression. Not surprisingly, an additional analysis controlling for the four demographic variables revealed that the three mental health variables were also strongly and positively correlated with each other; reported levels of PTSD were correlated with both anxiety scores and depression scores, and anxiety scores were correlated with depression scores (see Table 2).

The second key analysis involved a comparison of levels of the three mental health problems between Bosnian residents and refugees in the United States. To strictly assess how area of residence may influence levels of PTSD, anxiety, and depression, three univariate analyses of covariance (ANCOVAs) that measured differences in Bosnian residents' and refugees' levels of these three variables, while controlling for the unique influences of summed trauma experience scores, age, marital status, and gender, were conducted. Consistent with our hypothesis, a statistically significant difference in reported PTSD levels was found between Bosnian residents and refugees, $F$ (1, $122)=3.99, p<.05$. This difference was accounted for, as we had expected, by Bosnian refugees $(M=2.58, s d=$ $.71)$ reporting more symptoms of PTSD than Bosnian residents $(M=2.20, \mathrm{sd}=.78)$. However, our hypotheses that Bosnian refugees would report statistically significantly greater mean symptoms of anxiety and depression were not confirmed. The results of these tests showed that Bosnian residents and refugees reported similar levels of anxiety, $F$ $(1,122)=.30, p>.05$, and depression, $F(1,122)=.91, p>.05$.

\section{Discussion}

In the present study we found, consistent with past research (e.g., Herman, 1992; Weine et al., 1995), that exposure to wartime trauma is strongly associated with mental health problems. Specifically, we found that exposure to wartime trauma was strongly and significantly related to levels of PTSD, anxiety, and depression in samples of Bosnian residents and refugees living in the U.S. The strength of each relationship (all $r \mathrm{~s}>$.70) suggests that these 
relationships are quite robust. We also found, consistent with some past research (e.g., Hunt \& Gakenyi, 2005; Miller et al., 2002a; Spasojevic et al., 2002), that the experience of exile may make refugees more prone to experiencing mental health problems than similarly traumatized war survivors who remain in their home counties. Specifically, we found that, even when controlling for past exposure to wartime trauma and a host of demographic variables, the Bosnian refugees in our sample suffered from significantly greater levels of PTSD (though not anxiety or depression) than their Bosnian resident cohort. Thus, it seems likely that the experience of being a refugee, and the challenges associated with this experience (e.g., language and cultural differences from the majority of the population in the refugees' new host country), may exacerbate at least some of the mental health problems resulting from exposure to wartime trauma. These findings have important implications for the prevention and treatment of mental health problems, particularly in refugees.

Certainly one of the most important implications of our results, as well as those of similar research (e.g., Weine et al., 1995) is that reliable mental health screening or triage procedures should be in place when countries and communities accept large numbers of refugees from war-torn areas. Unfortunately, host communities are often overwhelmed by the many immediate needs of refugees, and as a result such mental health triage procedures are not effectively implemented. As Fowler and her colleagues (2005) report in their experiences of working with Canadian communities absorbing refugees from the humanitarian emergency in Kosovo, the sheer magnitude of refugee needs caught Canadian relief workers off guard, and these workers struggled mightily to offer treatment options and referrals to refugees with multiple and varying needs. They stressed the need for more effective triage at the outset of the relief effort, as well as a coordinated strategy for helping refugees access medical and mental health care and other transitional services. Other researchers (e.g., Pumagiera et al., 2005) agree with respect to the need for reliable triage, and argue that effective triage procedures may help refugees whom most need mental health treatment receive it in a timely manner. Given that our results show that those refugees who have experienced the greatest amount of war-related trauma tend to experience the greatest levels of PTSD, anxiety, and depression, it seems that an assessment of trauma exposure may be an important component of the triage process.

Of course, successfully identifying those individuals most likely to be in need of mental health services is only a first step in providing necessary care (Pumagiera et al, 2005). The provision of quality care to refugees is of utmost importance, and unfortunately, some research suggests that historically providers have been unprepared to offer such quality care (Onyut et al., 2004; Weine \& Henderson, 2005; Weine, Kuc, Dzudza, Razzano, \& Pavkovic, 2001). For example, Weine and Henderson (2005), in a review of mental health treatment provided to Bosnian refugees in Chicago, argued that many providers did not adequately screen for major mental health problems such as PTSD, and that many did not effectively educate refugees on the nature and symptoms of this common (at least among refugees) condition. Many other researchers (e.g., Bala, 2005; Bemak, 1989; Eth, 1992; Kinzie et al., 1988; Onyut et al., 2004; Pumagriega, Rogers, \& Rothe, 2005; Pumariega et al., 2005; Weine et al., 2004; Weine, Ware, \& Klebic, 2004) have argued for the need for cultural competence in the provision of services, correctly noting that many outreach efforts and therapeutic practices that work well with longtime citizens of a host country are not likely to be effective with a refugee population. Furthermore, there may be ethical concerns unique to refugee populations (for example, related to the receipt of informed consent, conflicting cultural values; Eth, 1992). Utilizing "cultural consultants" who have backgrounds similar to refugee populations in mental health service provision is one method relief workers and treatment providers can use to ensure culturally competent, quality mental health care (Kirmayer, Groleau, Guzder, Blake, \& Jarvis, 2003; Pumagiera et al., 2005).

Many researchers and therapists who work with refugee populations have developed creative intervention and treatment practices that appear effective and seem to avoid the pitfalls of culturally incompetent practices. Such pitfalls include conducting therapy in an environment that connotes one has a "mental problem," individual therapy that removes the refugee from his or her family or normal supports, and failing to incorporate or at least recognize culturally-specific methods of healing (Phan, 2000; Pumariega et al., 2005; Weine et al., 2005). Several promising treatment procedures that have been used with refugees are holistic in nature (e.g., Bala, 2005) and often feature interesting qualitative methodologies. For example, Neuner and his colleagues (2002) reported success in reducing PTSD symptoms in a severely traumatized Kosovar refugee with Narrative Exposure Therapy (NET), a combination of Cognitive Behavior Therapy and Testimony Therapy. NET may be particularly effective for use with refugees, as it allows for persons to discuss their traumatic experiences in a testimonial fashion (rather than a stigmatizing clinical fashion) and explicitly recognizes the role of human rights violations as causes of psychological distress (Nuener, Schauer, Roth, \& Elbert, 2002; for additional information on the value of "testimonies" as a therapeutic practice, see Weine [2000]). Other creative practices have involved utilizing art therapy, both with adults and 
children (Fitzpatrick, 2002; Kalmanowitz \& Lloyd, 1999) and fostering supportive social connections through the development of "emotional capital" in therapy groups (Garland, Hume, \& Majid, 2002). Art therapies may be particularly successful in use with refugees because they mask the clinical or diagnostic nature of the provider-client interaction, and group therapies may allow refugees to develop social supports and validate their common experiences in a less formal therapeutic setting.

Stevan Weine and his colleagues have recently developed some of the most creative and holistic approaches to intervention and treatment for refugees (e.g., Weine, 2000; Weine et al., 2004; Weine \& Henderson, 2005; Weine et al., 2003; Weine et al., 2003). These approaches may be the most promising, particularly for use with a Bosnian sample such as ours, as nearly all of Weine's work has been with Bosnian refugees who suffer or are at-risk of developing mental health problems as a result of traumatic exposure (Weine, 2000). Correctly noting that many past approaches to treating trauma-exposed refugees have focused on individual refugees and their personal mental health problems, usually in isolation, Weine (2000) argues that, because Bosnians view themselves as embedded in a larger network of family and community members, these traditional approaches are not likely to be efficacious. In contrast to these approaches, Weine (2000; see also Weine et al., 2004) argues for a family- or multifamily-oriented treatment approach that focuses on identifying strengths and competencies in family members or the unit as a whole. An example of such an approach is the Coffee and Family Education and Support for Bosnian Families (CAFES) project, which involves multiple family discussion groups designed to help families identify strengths and resources to help refugees overcome stressors associated with trauma and exile, and to link refugees with resource organizations that will help them access needed care and services. A major benefit of the CAFES project is that it builds upon a natural strength within Bosnian culture (i.e., families), while allowing refugees to address important mental health issues in a culturally non-threatening environment. Mental health approaches, such as the CAFES project, that are culturally appropriate and that help facilitate support building and service access and utilization (Weine \& Henderson, 2005) seem particularly well suited to address the psychological distress and disorientation experienced by many trauma survivors and refugees.

The results of this study seem to confirm that exposure to wartime trauma is associated with pathological levels of psychological distress, and that this distress may be greater for refugees than trauma survivors who remain in their own countries. Although it has been recognized that relief organizations and mental health providers have been overwhelmed by the needs of refugees in past humanitarian crises (Fowler et al., 2005), it is not unreasonable to believe that we as mental health professionals can learn from past mistakes. It seems quite likely that future efforts to provide services to refugees can be better organized, informed, and culturally competent, and therefore they can be more effective in the prevention and treatment of psychological distress in refugees. The innovative therapeutic approaches briefly described here seem promising for use among refugees such as those in our sample, as well as those scattered around the world, and we encourage further exploration of these and other techniques.

\section{Notes}

1 Bosnia and Herzegovina are two regions of the same country: Bosnia-Herzegovina. However, most of the literature describing Bosnia-Herzegovina (including most of that we have summarized here) refers to the entire country as "Bosnia" and the people who live in both Bosnia and Herzegovina as "Bosnian." For the sake of consistency, we do the same in this article.

2 Address correspondence and reprint requests to: Theodore W. McDonald, Department of Community and Environmental Health, Boise State University, 1910 University Drive, Boise, Idaho, 83725-1835.

As discussed in the Harvard Trauma Manual, Bosnia-Herzegovina Version (Allden et al., 1998c), both the HTQ and HSCL-20 were designed for use in an interview format during clinical intervention, rather than as self-report measures. However, because of practical difficulties associated with administering the measures in clinical interviews, the measures were completed in a self-report format. 


\section{References}

Ajdukovic, M. (1998). Displaced adolescents in Croatia: Sources of stress and posttraumatic stress reaction. Adolescence, 33, 209-217.

Allden, K., Franciskovic, T., Lavelle, J., Mathias, M., McInnes, K., Mollica, R. F., \& Moro, L. (1998a). Harvard Trauma Questionnaire: Bosnia-Herzegovina version. Cambridge, MA: Harvard Program in Refugee Trauma.

Allden, K., Franciskovic, T., Lavelle, J., Mathias, M., McInnes, K., Mollica, R. F., \& Moro, L. (1998b). Hopkins Symptom Checklist-25: Bosnia-Herzegovina version. Cambridge, MA: Harvard Program in Refugee Trauma.

Allden, K., Ceric, I., Kapetanovic, A., Lavelle, J., Loga, S., Mathias, M., McInnes, K., Mollica, R. F., Puratic, V., \& Sarajlic, N. (1998c). Harvard Trauma Manual: Bosnia-Herzegovina version. Cambridge, MA: Harvard Program in Refugee Trauma.

Bala, J. (2005). Beyond the personal pain: Integrating social and political concerns in therapy with refugees. In D. Ingleby (Ed.) Forced migration and mental health: Rethinking the care of refugees and displaced persons (pp. 169-182). New York: Springer Publishing.

Beiser, M., \& Fleming, J. A. (1986). Measuring psychiatric disorder among Southeast Asian refugees. Psychological Medicine, 16, 627-639.

Beiser, M., \& Hou, F. (2001). Language acquisition, unemployment and depressive disorder among Southeast Asian refugees: a 10-year study. Social Science \& Medicine, 53, 1321-1334.

Bemak, F. (1989). Cross-cultural family therapy with Southeast Asian refugees. Journal of Strategic \& Systematic Therapies, 8, 22-27.

Carballo, M., Smajkic, A., Zeric, D., Dzidowska, M., Gebre-Medhin, J., \& Van Halem, J. (2004). Mental health and coping in a war situation: the case of Bosnia and Herzegovina. Journal of Biosocial Sciences, 00, 1-15.

Clarke, G. N., Sack, W. H., \& Goff, B. (1993). Three forms of stress in Cambodian adolescent refugees. Journal of Abnormal Child Psychology, 21, 65-77.

Colic-Peisker, V., \& Walker, I. (2003). Human capital, acculturation and social identity: Bosnian refugees in Australia. Journal of Community \& Applied Social Psychology, 13, 337-360.

Chung, R. C. Y., \& Singer, M. K. (1995). Interpretation of symptom presentation and distress: A southeast Asian refugee example. Journal of Nervous and Mental Disease, 183, 639-648.

Derogatis, L. R., Lipman, R. S., \& Covi, L. (1973). The SCL-90: An oupatient psychiatric rating form. Psychopharmacological Bulletin, 9, 13-28.

Espino, C. M. (1991). Trauma and adaptation: The case of Central American children. In F. L. Ahearn and J. L. Athey (Eds.) Refugee children: Theory, research, and services (pp. 106-124). Baltimore, MD: Johns Hopkins University Press.

Eth, S. (1992). Ethical challenges in the treatment of traumatized refugees. Journal of Traumatic Stress, 5, $103-110$.

Fitzpatrick, F. (2002). A search for home: The role of art therapy in understanding the experiences of Bosnian refugees in Western Australia. Art Therapy, 19, 151-158.

Flaskerud, J. H., \& Anh, N. T. (1988). Mental health needs of Vietnamese refugees. Hospital \& Community Psychiatry, 39, 435-437. 
Fowler, N., Redwood-Campbell, L., Molinaro, E., Howard, M., Kaczorowski, J., Jafapour, M., Robinson, S. (2005). The 1999 international emergency humanitarian evacuation of the Kosovars to Canada: A qualitative study of service providers' perspectives at the international, national, and local levels. International Journal for Equity in Health. Retrieved March 28, 2006 from http://www.equityhealthj.com/content/4/1/1

Gafner, G., \& Benson, S. (2001). Indirect ego-strengthening in treating PTSD inimmigrants from Central America. Contemporary Hypnosis, 18, 135-144.

Garland, C., Hume, F., \& Majid, S. (2002). Remaking connections: Refugees and the development of emotional capital in therapy groups. Psychoanalytic Psychotherapy, 16, 197-214.

Geltman, P. L., Augustyn, M., Barnett, E. D., Klass, P. E., \& Groves, B. M. (2000). War trauma experience and behavioral screening of Bosnian refugee children resettled in Massachusetts. Journal of Developmental and Behavioral Pediatrics, 21, 255-261.

Herman, J. L. (1992). Complex PTSD: A syndrome in survivors of prolonged and repeated trauma. Journal of Traumatic Stress, 5, 377-391.

Hunt, N., \& Gakenyi, M. (2005). Comparing refugees and nonrefugees: The Bosnian experience. Journal of Anxiety Disorders, 19, 717-723.

Kalmanowitz, D., \& Lloyd, B. (1999). Fragments of art at work: Art therapy in the former Yugoslavia. Arts in Psychotherapy, 26, 15-25.

Keyes, E. F. (2000). Mental health status in refugees: An integrated review of current research. Issues in Mental Health Nursing, 21, 397-410.

Kinzie, J. D., Leung, P., Bui, A., Ben, R., Keopraseuth, K. O., Riley, C., Fleck, J., \& Ades, M. (1988). Group therapy with Southeast Asian refugees. Community Mental Health Journal, 24, 157-166.

Kirmayer, L., Groleau, D., Guzder, J., Blake, C., \& Jarvis, E. (2003). Cultural consultation: A model of mental health service for multicultural societies. Canadian Journal of Psychiatry, 48, 145-153.

Kocijan-Hercigonja, D., Rijavec, M., Marusic, A., \& Hercigonja, V. (1998). Coping strategies of refugee, displaced, and non-displaced children in a war area. Nordic Journal of Psychiatry, 52, 45-50.

Mghir, R., Freed, W., Raskin, A., \& Katon, W. (1995). Depression and posttraumatic stress disorder among a community sample of young adult Afghan refugees. Journal of Nervous and Mental Disease, 183, 24-30.

Miller, E. K., Weine, S. M., Ramic, A., Brkic, N., Djuric-Bjedic, Z., Smajkic, A., Boskailo, E., \& Worthington, G. (2002a). The relative contribution of war experiences and exile-related stressors to levels of psychological distress among Bosnian refugees. Journal of Traumatic Stress, 15, 377-387.

Miller, K. E., Worthington, G. J., Muzurovic, J., Tipping, S., \& Goldman, A. (2002b). Bosnian refugees and the stressors of exile: A narrative study. American Journal of Orthopsychiatry, 72, 341-354.

Mollica, R. F. (2001). The trauma story: A phenomenological approach to the traumatic life experiences of refugee survivors. Psychiatry, 64, 60-63.

Mollica, R. F., McInnes, K., Sarajlic, N., Lavelle, J., Sarajlic, I., \& Massagli, P. (1999). Disability associated with psychiatric comorbidity and health status in Bosnian refugees living in Croatia. Journal of the American Medical Association, 282, 433-439.

Mollica, R. F., Wyshack, G., de Marneffe, D., Khuon, F., \& Lavelle, J. (1987). Indochinese versions of the Hopkins Symptom Checklist-25: A screening instrument for the psychiatric care of refugees. American Journal of Psychiatry, 144, 497-500. 
Mooren, G. T. M., \& Kleber, R. J. (2001). The impact of war in Bosnia and Herzegovina: Devastated trust in Bosnia. International Journal of Mental Health, 30, 6-21.

Neuner, F., Schauer, M., Roth, W. T., \& Elbert, T. (2002). A narrative exposure treatment as intervention in a refugee camp: A case report. Behavioral and Cognitive Psychotherapy, 30, 205-210.

Onyut, L. P., Neuner, F., Schauer, E., Ertl, V., Ogenwald, M., Schauer, M., \& Elbert, T. (2004). The Nakivale Camp Mental Health Project: Building local competency for psychological assistance to traumatized refugees. Intervention: International Journal of Mental Health, Psychosocial Work \& Counseling in Areas of Armed Conflict, 2, 90-107.

Parloff, M. B., Kelman, H. C., \& Frank, J. D. (1954). Comfort, effectiveness, and self-awareness as criteria for improvement in psychotherapy. American Journal of Psychiatry, 3, 343-351.

Phan, T. (2000). Investigating the use of services for Vietnamese with mental illness. Journal of Community Health, $25,411-425$.

Powell, S., Rosner, R., Butollo, W., Tedeschl, R. G., Calhoun, L. G. (2003). Posttraumatic growth after war: A study with former refugees and displaced people in Sarajevo. Journal of Clinical Psychology, 59, 71-83.

Pumariega, A. J., Rogers, K., \& Rothe, E. (2005). Culturally competent systems of care for children's mental health: Advances and challenges. Community Mental Health Journal, 41, 539-555.

Pumariega, A. J., Rothe, E., \& Pumariega, J. B. (2005). Mental health of immigrants and refugees. Community Mental Health Journal, 41, 581-597.

Sack, W., Clarke, G., \& Seeley, J. (1996). Multiple forms of stress in Cambodian adolescent refugees. Journal of the American Academy of Child and Adolescent Psychology, 34, 1160-1166.

Silove, D. (1999). The psychological effects of torture, mass human rights violations, and refugee trauma: Toward an integrated conceptual framework. Journal of Nervous and Mental Disease, 187, 200-207.

Smith, P., Perrin, S., Yule, W., \& Rabe-Hesketh, S. (2001). War exposure and material reactions in the psychological adjustment of children from Bosnia-Hercegovina. Journal of Child Psychology and Psychiatry, 42, 395-404.

Spasojevic, J., Heffer, R. W., \& Snyder, D. K. (2000). Effects of posttraumatic stress and acculturation of marital functioning in Bosnian refugee couples. Journal of Traumatic Stress, 13, 205-217.

Sudetic, C. (1998). Blood and vengeance: One family's story of the war in Bosnia. New York: Penguin.

Thabet, A. A., Abed, Y., \& Vostanis, P. (2004). Comorbidity of PTSD and depression among refugee children during war conflict. Journal of Child Psychology and Psychology, 45, 533-542.

Thompson, M., \& McGorry, P. (1995). Psychological sequelae of torture and trauma in Chilean and Salvadorean migrants: A pilot study. Australian and New Zealand Journal of Psychiatry, 29, 84-95.

Thulesius, H., \& Hakansson, A. (1999). Screening for posttraumatic stress disorder symptoms among Bosnian refugees. Journal of Traumatic Stress, 12, 167-174.

Weine, S. (2000). Survivor families and their strengths: Learning from Bosnians after genocide. Other Voices: The (e)Journal of Cultural Criticism. Retrieved March 28, 2006 from http:

www.othervoices.org/2.1/weine/bosnia.html

Weine, S. M., Becker, D. F., McGlashan, T. H., Laub, D., Lazrove, S., Vojvoda, D., \& Hyman, L. (1995). Psychiatric consequences of "ethnic cleansing": Clinical assessment and trauma testimonies of newly resettled Bosnian refugees. American Journal of Psychiatry, 152, 536-542. 
Weine, S. M., Feetham, S., Kulauzovic, Y., Besic, S., Lezic, A., Mujagic, A., Muzurovic, J., Spahovic, D., Zhubi, M., Rolland, J., \& Pavkovic, I. (2004). Bosnian and Kosovar refugees in the United States: Family interventions in a services framework. In K.E. Miller \& L. M. Rasco (Eds.) The mental health of refugees: Ecological approaches to healing and adaptation (pp. 263-293). Mahwah, NJ: Lawrence Erlbaum.

Weine, S. M., \& Henderson, S. W. (2005). Rethinking the role of posttraumatic stress disorder in refugee mental health services. In T. A. Corales (Ed.) Trends in posttraumatic stress disorder research (pp. 157-183). Hauppauge, NY: Nova Science Publishers.

Weine, S. M., Knafl, K., Feetham, S., Kulauzovic, Y., Klebic, A., Sclove, S., Besic, S., Mujagic, A., Muzurovic, J., \& Spahovic, D. (2005). A mixed methods study of refugee families engaging in multiple family groups. Family Relations: Interdisciplinary Journal of Applied Family Studies, 54, 558-568.

Weine, S. M., Kulauzovic, Y., Besic, S., Lezic, A., Mujagic, A., Muzurovic, J., Spahovic, D., Feethham, S., Ware, N., Knafl, K., \& Pavkovic, I. (2004). Family consequences of refugee trauma. Family Process, 43, 147-160.

Weine, S. M., Kuc, G., Dzudza, E., Razzano, L., \& Pavkovic, I. (2001). PTSD among Bosnian refugees: A survey of providers' knowledge, attitudes and service patterns. Community Mental Health Journal, 37, 261-271.

Weine, S. M., Vijvoda, D., Becker, D. F., McGlashan, T. H., Hodzic, E., Laub, D., Hyman, L., Sawyer, M., \& Lazrove, S. (1998). PTSD symptoms in Bosnian refugees one year after resettlement in the United States. American Journal of Psychiatry, 155, 562-564.

Weine, S. M., Ware, N., \& Klebic, A. (2004). Converting cultural capital among teen refugees and their families from Bosnia-Herzegovina. Psychiatric Services, 55, 923-927.

Witmer, T. A. P., \& Culver, S. M. (2001). Trauma and resilience among Bosnian refugee families: A critical review of the literature. Journal of Social Work Research and Evaluation, 2, 173-187. 
Table 1

Summed Trauma Experiences as a Function of Respondent Marital Status

\section{Respondent Marital Status}

\begin{tabular}{lccc}
\hline & Single & Married & Widowed \\
\cline { 2 - 4 } Mean Summed Trauma & $74.82^{\mathrm{a}}$ & $87.21^{\mathrm{b}}$ & $116.07^{\mathrm{c}}$ \\
Experiences & $(23.39)$ & $(23.88)$ & $(21.08)$ \\
\hline
\end{tabular}

Note. Superscripts indicate significant differences across rows. Numbers in parentheses are standard deviations. 
Table 2

Intercorrelations Between Summed Trauma Experiences (STE), and Post-Traumatic Stress

Disorder (PTSD), Anxiety, and Depression Scores

\begin{tabular}{|c|c|c|c|c|}
\hline Variable & STE & PTSD & Anxiety & Depression \\
\hline STE & 1.00 & $.94 * * *$ & $.72 * * *$ & $.75 * * *$ \\
\hline PTSD & & 1.00 & $.74 * * *$ & $.75 * * *$ \\
\hline Anxiety & & & 1.00 & $.74 * * *$ \\
\hline Depression & & & & 1.00 \\
\hline
\end{tabular}

Note. $\mathrm{df}=122$ in all comparisons. $* * *$ denotes statistical significance at $p<.001$. 